\title{
Politólogos. Subcampos y criterios para una propuesta de educación profesionali
}

\section{Political Scientists, Subfields, and Criteria for a Professional Education Proposal}

\author{
Por: Javier Duque Daza ${ }^{1}$
}

1. Profesor Universidad del Valle, Politólogo. PhD Ciencia política, Flacso, México. Cali, Colombia. Orci: org/0000-0001-9996-483 perfil Google: https://scholar.google. com/citations?user=n3aq-cwAAAAJ\&hl=es Contacto: Jduqued86@hotmail.com

OPEN ACCESS

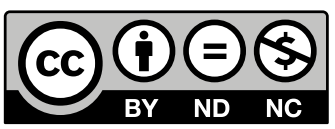

Copyright: @ $\odot 2019$ El Ágora USB.

La Revista El Ágora USB proporciona acceso abierto a todos sus contenidos bajo los términos de la licencia creative commons AtribuciónNoComercial-SinDerivar 4.0 Internacional (CC BY-NC-ND 4.0)

Tipo de artículo: revisión Recibido: octubre de 2018 Revisado: noviembre de 2018 Aceptado: enero de 2019 Doi: 10.21500/16578031.3759

Citar así: Duque Daza, J. (2019) Politólogos. Subcampos y criterios para una propuesta de educación profesional. EI Ágora USB, 19(2). 559-582. DOI:

$10.21500 / 16578031.3759$

\section{Resumen}

Este artículo realiza un análisis de las tendencias de educación de politólogos, sus fundamentos, orientaciones, subcampos y líneas centrales de desarrollo. A partir de este análisis se propone los fundamentos y criterios que pueden ser considerados en el diseño de una propuesta curricular para el pregrado en ciencia política. El argumento central es que en cualquier disciplina los nuevos miembros son educados a partir de ciertos estándares sobre teorías y conceptos, metodologías y técnicas, que le los diferencias de otras disciplinas y profesiones. Aunque hay diferencias en los énfasis formativos, en las preferencias teóricas, en las concepciones y valores, y la disciplina supone el pluralismo teórico y metodológico, existen componentes mínimos básicos comunes a todos los politólogos que deben hacer parte de los diseños curriculares.

Palabras clave. Ciencia política; politólogo; política; currículo de pregrado.

\section{Abstract}

This article performs an analysis of the education trends of political scientists, their fundamentals, orientations, subfields, and central lines of development. From this analysis, the fundamentals and criteria, which can be considered in the design of a curricular proposal for the undergraduate program in political science, are proposed. The central argument is that in any discipline, new members are educated from certain standards on theories and concepts, methodologies, and techniques, which differentiates them from other disciplines and professions. Although there are differences in formative emphasis, theoretical preferences, conceptions and values, and discipline, involves theoretical and methodological pluralism, there are minimum basic components common to all political scientists, who must be part of the curriculum designs.

Keywords. Political Science; Political Scientist; Policy/Politics; and Undergraduate Curriculum. 


\section{Introducción}

La ciencia política es una de las ciencias sociales de origen decimonónico que se ha consolidado a lo largo del último siglo y sus principales componentes disciplinares se han ido consolidado en los diferentes países, aunque de forma desigual. La ciencia política ha ido avanzando en su proceso de institucionalización.

Estos avances presentan, sin embargo, algunas tensiones e incertidumbres. Una mirada a los contenidos de las convocatorias de los congresos de las principales asociaciones internacionales y a los temas que suelen incluirse en los manuales internacionales que son referentes de la disciplina permite ver que hay una proliferación expansiva de secciones, subcampos, áreas o líneas temáticas o de trabajo. De esta explosión han resultados decenas de tópicos y temáticas abordados por los politólogos, también ha emergido espacios híbridos en los que la ciencia política se combina con otras disciplinas y/o temáticas abordadas por estas. Esta situación ha derivado en cierta visión de una disciplina sin confines, abierta a todo, a lo nuevo y a lo viejo, a lo novedosos y a lo tradicional. Una imagen de un supuesto caos en donde no es clara la cuestión respecto a qué es lo que distingue a la disciplina de otras, de qué se ocupa, que no se ocupen otras disciplinas sociales, o de qué se ocupa de forma diferenciada a las demás.

Respecto a este crecimiento exponencial de temas y problemas que suelen ser considerados propios de la ciencia política surgen algunas preguntas relacionadas con la formación básica del politólogo: ¿frente a tal amplitud de temas y áreas, en qué debe enfocarse la formación de los politólogos? ¿cuáles áreas, líneas, subcampos formativos pueden considerarse centrales y fundamentales en la formación académica básica? ¿qué es lo que distingue a la disciplina de otras en cuanto al campo, su objeto y los subcampos de que se ocupa? ¿es válido hablar de unos temas, áreas o problemas centrales que constituyan la formación mínima profesional del politólogo que incorpore un núcleo central claro y estándar?

Este artículo se ocupa de estas cuestiones. El argumento que se sustenta es que en cualquier disciplina los nuevos miembros, quienes se están formando en su campo y aspiran a ingresar a la comunidad académica, son socializados y formados a partir de ciertos estándares integrados por teorías y conceptos, metodologías y técnicas que en su conjunto le imprimen la especificidad de la formación que la diferencian de otras disciplinas y profesiones y que se convierten en códigos que dan cuenta de una formación común y le confieren identidad a los profesionales. Asimismo, aunque hay diferencias en los énfasis formativos, en las preferencias teóricas, en las concepciones y valores, y la disciplina supone el pluralismo teórico y metodológico, existen componentes mínimos básicos comunes a todos los politólogos. Si bien es claro que hay diferencias y divergencias en la formación de los politólogos, también hay acuerdos y convergencias, de tal forma que se puede plantear de forma razonable un núcleo formativo básico común, una formación mínima profesional del politólogo. Como lo expresa Luigui Graziano (1986): "toda disciplina debe madurar una identidad cultural, pero también una identidad operativa: 1os que la cultivan deben saber qué es legítimo hacer y qué no lo es, qué campos y métodos es legítimo cultivar, para cualificarse -a los ojos de la comunidad científica- precisamente como cultivadores".

A partir de este argumento se desarrollan tres ideas: la primera es que la tesis del caos disciplinar de la Ciencia Política es aparente, o al menos relativa, por cuanto, en medio de la proliferación de temas, problemas y de las diferencias hay un orden subyacente producto del propio proceso constitutivo de la disciplina; la segunda idea se refiere a los contenidos de este orden subyacente que configuran ciertos confines flexibles de la disciplina; la tercerea deviene en una propuesta de un esquema de subcampos que pueden dar paso a un núcleo formativo de los politólogos, además de algunos saberes híbridos y otros tópicos emergentes en la disciplina. 
En la construcción del argumento primero de presenta y se discute la tesis de la existencia de un relativo caos disciplinar en la disciplina con base los planteamientos de autores de Estados Unidos y América Latina y una mirada a las orientaciones básicas de las mallas curriculares de las principales universidades de América latina. Luego se recurre al análisis de las tres organizaciones académicas que convocan periódicamente a politólogos de todo el mundo, International Political Science Association (IPSA), American Political Science Association (APSA) y la Asociación Latinoamericana de Ciencias Políticas (ALACIP). Estas organizaciones realizan sus congresos de forma regular, cuentan con centenares de afiliados, tiene sus propias publicaciones y espacios de socialización profesional. Se compararon y analizaron las áreas o líneas temáticas de sus recientes convocatorias junto con la agrupación temática presentada en del The Oxford Handbooks of Political Science (2009) compilado por Robert E Goodin, que incluye trabajos y estados del arte elaborados por politólogos de amplia trayectoria y reconocimiento, lo cual supone su competencia para dar cuenta de los diferentes subcampos de la disciplina, además de los subcampos que incluye dentro de la disciplina la Enciclopedia Británica.

Con el análisis y la comparación se concluye que a pesar de la proliferación de temas, áreas o líneas, se presentan convergencias importantes, intersecciones en todas las asociaciones y en el Handbook en torno a nueve tópicos que podemos considerar como subcampos de la ciencia política, lo cual permite tener una visión general de lo que podría ser la base de la formación mínima profesional. Al final se toman estos subcampos y se desagregan algunas líneas temáticas centrales para proponer un marco general de una malla curricular de formación del politólogo. De forma adicional, se considera que la ciencia política, de igual forma que las demás ciencias sociales, suelen converger con otras disciplinas en el análisis de problemas complejos, se recupera el planteamiento de los campos híbridos del saber cómo un espacio que debe también incluirse en la formación del politólogo sin que se pierda la perspectiva formativa, campos como la sicología política, la sociología política, la historia política, la economía política, la antropología política. Finalmente, como las disciplinas son dinámicas y las sociedades cambian cada vez con mayor velocidad, se incluye un espacio complementario para la innovación y las temáticas emergentes, que no deben excluirse de las posibilidades formativas del politólogo.

\section{¿Un caos disciplinar? Los subcampos de la ciencia política}

La ciencia política se caracteriza por la presencia de algunas disputas y controversias intelectuales sobre su objeto de estudio (que presenta una tendencia a resolverse en torno al poder político limitado socialmente); sobre la pluralidad de teorías, algunas de las cuales están en abierta confrontación y que impiden la búsqueda de ciertos consensos que harían avanzar la disciplina (esto está presente en todas las ciencias sociales y en el estado actual del conocimiento resulta inevitable); sobre la medición y la cuantificación que tiende a ser predominante entre académicos norteamericanos y en sus áreas de influencia (frente a lo cual han surgido corrientes que lo cuestionan y reivindican la importancia de otras estrategias cualitativas); sobre la posibilidad de alcanzar ciertos acuerdos conceptuales y de avanzar de forma acumulativa (en lo que han terciado también los filósofos políticos); mientras que algunos como Giovanni Sartori impulsaron un proyecto sobre el debate y la posibilidad de alcanzar ciertos consensos conceptuales otros señalan que esto es imposible, como Danilo Zolo (2006). Sobre las relaciones entre el saber académico y la militancia política. A estas y otras tensiones se ha sumado la discusión sobre la forma como ha crecido y se ha cualificado la disciplina, específicamente sobre la proliferación de temas y problemas de estudio que se refleja en los eventos internacionales, en las publicaciones y en los contenidos curriculares de los programas de pregrado. Esta dinámica de la disciplina ha dado origen a la percepción de que existe, en palabras de David Laitin 
(2004), una anarquía y a un caos disciplinar. Surge la imagen de una disciplina sin confines y en expansión permanente.

Señala, por una parte, que hay una multiplicidad de orientaciones, contenidos, temáticas, líneas académicas, secuencias y formas de organizar las estructuras curriculares de los programas de pregrado o licenciatura de ciencia política. Con referencia a Estados Unidos, tras una evaluación de los programas en las universidades de más prestigio, Laitin planteó algunas conclusiones que pueden servir para reflexionar y, tal vez, para hacerlas extensivas de forma hipotética a otras partes del mundo como Europa y América Latina: (a) no existe un curso general introductorio estándar en ciencia política que ubique a los estudiantes respecto al objeto de estudio y los aproxime a ciertos tópicos básicos de la disciplina, a sus líneas y campos, autores clásicos y a los enfoques más relevantes; (b) no hay una orientación que permita unificar los currículos con ciertos estándares, cada escuela produce sus politólogos con sus orientaciones, énfasis y modos particulares de ver la disciplina; (c) en muy pocos casos existen pre requisitos para los cursos superiores, lo cual hace que los profesores se enfrenten a estudiantes con diversos niveles de formación, que no cuentan con los fundamentos necesarios para avanzar de forma significativa; (d) hay una alta fragmentación en enfoques, teorías y metodologías, con lo cual impera una imagen de ausencia de un núcleo disciplinar, de autores centrales y clásicos. La imagen de la disciplina es de un espejo quebrado en múltiples partes, sin que pueda reflejarse algo claro en él. Un similar planteamiento fue hecho por Gerardo Mounk y Richard Snyder cuando señalan que hay diferencias apreciables incluso entre instituciones de un mismo país, con variaciones significativas respecto al rol social del politólogo, su formación y lo que significa hacer ciencia política en uno u otro contexto científico-académico (Munck \& Snyder, 2007).

En América Latina esta situación es aún más acentuada y no solo se trata de la gran diversidad y heterogeneidad, también se refleja en una precaria demarcación de las estructuras curriculares respecto a la disciplina. Hay una gran heterogeneidad en los procesos de institucionalización de la disciplina y en aquellos países en donde tiene un mayor desarrollo se suma a disparidad, las múltiples posturas sobre qué es ser un politólogo y sobre qué contenidos son centrales y cuál debe ser su formación básica fundamental (Bulcourf \& Cardozo, 2012).

En algunos países se enseñan bajo la denominación de ciencia política contenidos y temáticas que corresponden al amplio campo de las ciencias sociales y al derecho o la sociología y no existe una comunidad de politólogos constituida que le de soporte a la enseñanza y a la investigación disciplinar. En cuanto al contenido de las mallas curriculares hay un subgrupo de países en los que existen programas de ciencia política que en realidad ofrecen una formación ambigua con la agregación de asignaturas de diversas ciencias sociales, de derecho, algunas historias nacionales, cursos de estadísticas y algunas asignaturas que corresponden a los subcampos de la ciencia política, pero en conjunto son solo una porción menor de las mallas curriculares. No hay claridad respecto a qué es la formación de un politólogo. Esto sucede en Paraguay, en el que los tres programas de ciencia política de las universidades mejor posicionadas son una mezcla de disciplinas sociales con algunas asignaturas aisladas sobre política y sin tramos formativos claros, continuidad ni tampoco niveles de cualificación progresiva. Por ejemplo, en la Universidad Central de Paraguay (Universidad Central del Parguay, s.f); la Universidad Nacional de Asunción hay una licenciatura en ciencia política de ocho semestres, que también contiene un abanico de las ciencias sociales, aunque con un poco más de asignaturas propias de la disciplina (Universidad Nacional de Asunción, 2007), y en la Universidad Nacional del Este hay una licenciatura en ciencia política que solo contiene cursos aislados de la disciplina (Univesidada Nacional del Este, 2004). 
Igual ocurre en Guatemala, sobre la cual Dinorah Azpuru (2005) acota que los tres programas que hay van más allá de la disciplina y han optado por una formación multidisciplinarios que incluyen cursos de ciencia política, relaciones internacionales y sociología, pero también otros de áreas como el derecho, la economía, la administración pública. Muchos de los docentes en las carreras de ciencia política no son politólogos, sino especialistas en otras ramas de las ciencias sociales; la producción académica de los politólogos que viven en el país es limitada y la mayoría se dedican a otras actividades y no a la investigación. Igual situación se presenta en:

República Dominicana: Solo hay ciencia política en la Universidad Autónoma de Santo Domingo, un programa ofertado por la Facultad de Ciencias Jurídicas y Políticas, hay asignaturas de diversas ciencias sociales y algunas pocas de ciencia política, véase: Universidad Autónoma de Santo Domingo, Facultad de Ciencias Jurídicas y Política, Licenciatura en Ciencias Política (Universidad Autónoma de Santo Domingo, 2018).

Honduras: En este país no existen pregrados en la disciplina, en la principal institución universitaria, la Universidad Nacional Autónoma de Honduras, hay una maestría en ciencia política y que ofrece la Facultad de Ciencias Jurídicas, consta de tres semestres y 22 asignaturas, la mayoría de estas no tienen relación con la ciencia política (Universidad Nacional Autónoma de Honduras, 2018).

Panamá: En la Universidad de Panamá hay una licenciatura en ciencia política y en esta hay asignaturas de Derecho, Sociología, Economía, Geografía, Medio ambiente, Historia, además de las didácticas. Es una formación más genérica que disciplinar (véase: Universidad de panamá, facultad de derecho y Ciencia política, Licenciatura en Ciencia Política (Universidad de Panamá, 2018).

También en Perú la disciplina está muy débilmente institucionalizada y solo hay ocho licenciaturas, cinco de ellas creadas en la última década y la más antigua es de finales de la década de 1980. La profesión de politólogo está emergiendo y hay una gran diferencia en la infraestructura, en los planes de estudios y en los grados y títulos ofrecidos por estas universidades. Igualmente, se constata la dispersión de enfoques, dando lugar a una tensión entre un perfil académico, uno orientado a la profesionalización e, incluso, uno más humanístico (Ramos, 2016). En cuanto a lo que se enseña, en lo que se forman los politólogos peruanos, algunos programas incluyen una amalgama de ciencia sociales con asignaturas de ciencia política, por ejemplo, en la Universidad Nacional Federico Villareal, el plan de estudios incluye sociología, economía, sicología, historia, antropología, ecología, derecho (cuatro cursos). También hay asignaturas propias de los subcampos de la ciencia política, cierto énfasis en el ámbito internacional (Universidad Nacional Federico Villareal, 2018), en otras universidades los programas combinan ciencias sociales, humanidades y, en menor medida, algunos subcampos de la ciencia política El programa de ciencia política de la Universidad Nacional Mayor de San Marcos incluye cursos de lenguaje y comunicación, proceso histórico-cultural del Perú, ética, diversidad cultural, arte y literatura del Perú, latinoamericana y universal, cambio climático, economía, género, música, cine. Algunas pocas asignaturas de pensamiento político, teorías del Estado, teorías del poder, relaciones internacionales, partidos políticos, sistemas electorales, comportamiento político, derecho, economía, estadística (Universidad Mayor Nacional de San Marcos, 2018).

En menor proporción, otros programas de grado van adquiriendo un claro perfil politológico. Es el caso del programa de la Pontificia Universidad Católica del Perú. Los cuatro primeros semestres son genéricos o de estudios generales e incluyen historia del siglo XX, matemáticas, escritura e interpretación, antropología, economía, sociología, elementos de ciencia política, derecho y otros cursos electivos. Desde el $\mathrm{V}$ al $\mathrm{X}$ semestre incluyen asignaturas claramente politológicas: teoría política, Estado y política en Perú y en el mundo contemporáneo, políticas públicas, gestión pública, política comparada, relaciones 
internacionales, partidos y sistemas de partidos, economía política, derecho constitucional y política, teorías de la democracia, métodos de investigación en ciencia política (Pontificia Universidad Católica del Perú, 2018). El programa de ciencia política de la Universidad Antonio Ruiz de Montoya incluye cursos de literatura universal y latinoamericana e historia, pero es el programa de Perú que contiene más asignaturas referidas a temas de ciencia política (Universidad Antonio Ruiz Montoya, 2018).

En general, la gran mayoría de estos planes de estudio no tienen un perfil disciplinar claro, con un gran peso de asignaturas de derecho y de historia. Se aplica en estos casos la afirmación de Dieter Nohlen respecto a que la debilidad de las ciencias sociales como el predominio de una de ellas en los programas denominados ciencia política representan un obstáculo para el establecimiento de la disciplina. Con el predominio de la sociología, la historia o el derecho, sus enfoques y tradiciones teóricas hacen que se niegue la autonomía de lo político y, por consiguiente, la necesidad de una disciplina específica dedicada al análisis de la política. Se asume que otras disciplinas sociales se pueden ocupar y tener como objeto de estudio y reflexión los problemas propios de la política (Nohlen, Ciencia política en América Latina, 2006).

En los países en donde el proceso de institucionalización disciplinar ha avanzado más, hay una tradición de varias décadas en las cuales se han ido perfilando programas con mucha influencia de Estados Unidos, con presencia de asignaturas y contenidos propios de los subcampos de la disciplina, temas, teorías, autores y obras referentes de la disciplina. En estos países hay un mayor número de doctores formados en ciencia política en Europa y Estados Unidos, predominan los politólogos sobre los profesores formados en otras disciplinas, hay mayor interacción con académicos de otros países (con intercambios, proyectos colectivos, asistencia frecuente a eventos académicos internacionales, publicaciones en revistas de prestigio) y las universidades cuentan con el ciclo formativo completo de grado, maestría y doctorado en la disciplina. Esto se pone de manifiesto en las universidades de mayor prestigio, la mayoría de ellas ubicadas en las capitales o principales ciudades, es el caso de:

México, una muestra, dos programas en instituciones de prestigio que tienen autonomía respecto al Derecho y los estudios jurídicos e incluyen en sus mallas curriculares un mayor número de asignaturas disciplinares propias del núcleo de los subcampos politológicos. En la Licenciatura de Ciencia política de la Universidad Nacional Autónoma de México predominan las asignaturas típicas de la disciplina (véase: UNAM, facultad de Ciencias políticas y Sociales, Ciencia Política (Universidad Nacional Autónoma de México, 2018), en el programa de Ciencia política del Instituto Tecnológico Autónomo de México, ITAM, también hay una clara orientación disciplinar (ITAM, 2018).

Chile, en la Universidad Católica de Chile hay un claro perfil disciplinar desde el primer semestre (Universidad Católica de Chile, s.f) y en el instituto de Ciencia Política, licenciatura Ciencia Política.

Uruguay, En la Universidad de la República hay una situación intermedia pues las disciplinas sociales de Desarrollo, Sociología, Trabajo social y Ciencia política comparten un ciclo básico los cuatro primeros semestres y en los otros seis Ciencia Política tiene un fuerte contenido disciplinas con asignaturas como teoría política, tres niveles; instituciones, tres niveles; Estado y políticas públicas, cuatro semestres; sistema político nacional, tres semestres; análisis comparado y otras cuatro asignaturas metodológicas (Universidad de la República, s.f).

Así mismo Brasil, parcialmente Colombia y Argentina (Bulcourf P. A., 2012).

En Colombia los programas de pregrado (actualmente hay 35) presentan énfasis diferentes, algunas asignaturas de temas regionales y algunos están muy influenciados aún por el Derecho, pero en la mayoría de los programas se puede identificar un núcleo común 
en torno a nueve asignaturas: Relaciones Internacionales; Política comparada; Introducción a la ciencia política; Teoría política; Teoría del Estado/Estado y globalización; Partidos y/o sistemas de partidos; Participación (incluye la acción colectiva y los movimientos sociales); Política comparada y Sistemas electorales. Especialmente en los programas de universidades ubicadas en Bogotá, Medellín y Cali tienen una orientación más disciplinar, mientras que las de universidades de ciudades más pequeñas tienden a ser multidisciplinares (Ver: (Duque Daza, 2014a); (Duque Daza, 2014b).

Hay que resaltar que hay en estos países muchas asimetrías y marcadas diferencias entre las universidades con mayor desarrollo ubicado en las capitales y en algunas otras ciudades principales, y las de provincia, en muchas de las cuales los programas de grado siguen siendo una mezcla de diferentes ciencias sociales.

Por otra parte, volviendo al diagnóstico de Laitin, además de las diferencias en la enseñanza de la disciplina (asignaturas), hay una desordenada proliferación de líneas de trabajo y especialidades que expresan una alta fragmentación que se manifiesta en los encuentros internacionales de la disciplina y que no obedece a criterio académicos que den cuenta del surgimiento y consolidación de nuevos espacios académicos que enriquezcan la disciplina, sino al predominio de un estilo de trabajo en el que cada quien pretende construir su propio nicho, su espacio temático identitario. Esta dinámica refleja la presencia de ciertos liderazgos académicos con capacidad de proponer y de crear nuevos paneles, comités o áreas de trabajo en las asociaciones a través de los cuales se articulan politólogos que hacen presencia institucional con sus propias líneas de trabajo que coordinan con otros investigadores nacionales o extranjeros, surgen así campos "autoproclamados" que impiden que se pueda establecer algún orden del campo de conocimiento. Con base en lo que ha ocurrido en APSA, Laitin describe la forma como se pasó de diecinueve subcampos en 1990, a treinta y uno en el año 2001, lo cual expresa esa tendencia creciente de fragmentación y de surgimiento de líneas y sub-líneas que pueden indicar una mayor riqueza y nuevos ámbitos de estudio de la disciplina, pero también denotan la fragmentación y la sobre especialización cuyos motivos no siempre son claramente expresados ni son exclusivamente académicos.

Si retomamos este segundo planteamiento de Laitin y vamos más allá de la ciencia política de Estados Unidos, observamos la misma tendencia en otros países, y en las organizaciones internacionales de la disciplina: se observa un abanico que se despliega y muestra una diversidad y multiplicidad de temáticas. Una forma de ilustrar lo anterior es comparando las 45 secciones de trabajo de APSA, los 49 comités de IPSA y las 22 mesas de trabajo de los Congresos de ALACIP de 2018 y 2017. Ver tabla 1.

Tabla 1

Líneas institucionales de trabajo y áreas de trabajo en ciencia política

\begin{tabular}{|l|l|l|}
\hline $\begin{array}{l}\text { American Political Science } \\
\text { Association APSA (2018) } \\
\text { Secciones organizadas }\end{array}$ & $\begin{array}{l}\text { International Political Science Association, } \\
\text { IPSA (2018) Comités de investigación }\end{array}$ & $\begin{array}{l}\text { Asociación Latinoamericana de } \\
\text { Ciencias Políticas (ALACIP IX } \\
\text { Congreso de 2017) } \\
\text { Áreas temáticas }\end{array}$ \\
\hline $\begin{array}{l}\text { 1. Federalismo y relaciones } \\
\text { intergubernamentales }\end{array}$ & 1. Conceptos y métodos. & $\begin{array}{l}\text { 1. Actores sociales: sindicatos, } \\
\text { grupos y M. Sociales }\end{array}$ \\
\hline 2. Leyes y cortes & 2.Elites políticas & $\begin{array}{l}\text { 2. Comportamiento político, } \\
\text { electoral y liderazgo }\end{array}$ \\
\hline 3. Estudios legislativos & 3. Unificación europea & $\begin{array}{l}\text { 3. Democracia, democratización } \\
\text { calidad de la democracia. }\end{array}$ \\
\hline 4. Política pública & $\begin{array}{l}\text { 4. Estudios comparados de gobiernos } \\
\text { locales }\end{array}$ & 4. Economía política. \\
\hline
\end{tabular}




\begin{tabular}{|c|c|c|}
\hline $\begin{array}{l}\text { 5. Partidos y organizaciones } \\
\text { políticas }\end{array}$ & 5. Sociología política & $\begin{array}{l}\text { 5. Estado y administración } \\
\text { pública. }\end{array}$ \\
\hline 6. Administración pública & 6. Mujer y política & 6. Estudios legislativos. \\
\hline 7. Procesamiento de conflictos & 7. estudios legislativos & 7. Estudios sobre ciudadanía \\
\hline $\begin{array}{l}\text { 8. Sistema electoral y } \\
\text { representación }\end{array}$ & 8. Estudios legislativos comparados. & $\begin{array}{l}\text { 8. Historia y enseñanza de la } \\
\text { ciencia política. }\end{array}$ \\
\hline $\begin{array}{l}\text { 9. Presidentes y política } \\
\text { ejecutiva }\end{array}$ & 9. Democracia electrónica. & $\begin{array}{l}\text { 9. Metodología de la } \\
\text { investigación }\end{array}$ \\
\hline 10. Metodología política & 10. Ciencia y política. & $\begin{array}{l}\text { 10. Militares y regímenes } \\
\text { militares }\end{array}$ \\
\hline 11. Religión y política & 11. Biología y política. & $\begin{array}{l}\text { 11. Opinión pública y } \\
\text { comunicación pública }\end{array}$ \\
\hline 12. Política urbana local & $\begin{array}{l}\text { 12. Democratización en perspectiva } \\
\text { comparada }\end{array}$ & $\begin{array}{l}\text { 12. Partidos y sistemas de } \\
\text { partidos }\end{array}$ \\
\hline $\begin{array}{l}\text { 13. Ciencia, tecnología y } \\
\text { política ambiental }\end{array}$ & 13. Política y etnicidad & 13. Poder ejecutivo y gobierno \\
\hline $\begin{array}{l}\text { 14. Mujer e investigación } \\
\text { política }\end{array}$ & 14. Política y geografía cultural. & $\begin{array}{l}\text { 14. Poder judicial, derechos } \\
\text { humanos y justicia }\end{array}$ \\
\hline $\begin{array}{l}\text { 15. Fundamentos de teoría } \\
\text { política }\end{array}$ & 15. Pluralismo socio-político & 15. Política comparada \\
\hline $\begin{array}{l}\text { 16. Información, tecnología y } \\
\text { política }\end{array}$ & 16. Opinión pública comparada & 16. Política e historia \\
\hline $\begin{array}{l}\text { 17. Seguridad internacional y } \\
\text { control de armas }\end{array}$ & 17. Estudios de Asia y del Pacífico & $\begin{array}{l}\text { 17. Política internacional, } \\
\text { relaciones internacionales }\end{array}$ \\
\hline 18. Política comparada & 18. Género, política y políticas. & $\begin{array}{l}\text { 18. Política subnacional y } \\
\text { urbana, descentralización }\end{array}$ \\
\hline $\begin{array}{l}\text { 19. Política y sociedad en } \\
\text { Europa }\end{array}$ & 19. Política, finanzas y corrupción & $\begin{array}{l}\text { 19. Política, cultura, ideología y } \\
\text { discursos }\end{array}$ \\
\hline 20. Estado, política y políticas & 20.Socialización política y educación & 20.Política, género y diversidad \\
\hline 21. Comunicación política & 21. Comunicación política. & 21. Políticas públicas \\
\hline 22. Política e historia & 22. Elecciones, ciudadanos y partidos. & 22. Teorías políticas \\
\hline 23. Economía política & 23. Fuerzas armadas y sociedad. & \\
\hline 24. Nueva ciencia política. & 24. Política comparada en salud. & \\
\hline 25.Psicología política & 25. Derechos humanos. & \\
\hline 26. Educación y ciencia política & 26. Estructura y organización del gobierno. & \\
\hline 27. Política, literatura y cine. & $\begin{array}{l}\text { 27. federalismo comparado y gobernanza } \\
\text { multinivel. }\end{array}$ & \\
\hline 28. Política exterior & 28. Sicología política. & \\
\hline $\begin{array}{l}\text { 29. Elecciones, opinión pública } \\
\text { y comportamiento del voto }\end{array}$ & 29. Política pública comparada. & \\
\hline 30. Raza etnicidad y política & 30. Filosofía política. & \\
\hline $\begin{array}{l}\text { 31. Historia internacional y } \\
\text { política }\end{array}$ & 31. Política pública y administración. & \\
\hline $\begin{array}{l}\text { 32. Democratización } \\
\text { comparada }\end{array}$ & $\begin{array}{l}\text { 32. El estudio de la ciencia política como } \\
\text { disciplina. }\end{array}$ & \\
\hline 33. Derechos humanos & 33. Calidad de la democracia. & \\
\hline $\begin{array}{l}\text { 34. Multimétodos cualitativos } \\
\text { de investigación }\end{array}$ & 34. Tecnología y desarrollo & \\
\hline 35. Sexualidad y política & 35. Poder político. & \\
\hline $\begin{array}{l}\text { 36. Sexualidad, política y } \\
\text { políticas }\end{array}$ & 36. Política y negocios. & \\
\hline
\end{tabular}




\begin{tabular}{|c|c|c|}
\hline 37. Política canadiense & $\begin{array}{l}\text { 37. Estado de bienestar y sociedad } \\
\text { desarrolladas. }\end{array}$ & \\
\hline 38. Redes políticas & 38. ¿Nuevo orden mundial? & \\
\hline 39. Investigación experimental & 39. Geopolítica & \\
\hline 40. Migración y ciudadanía & 40.Seguridad, integración y unificación. & \\
\hline 41. Política africana & 41. Religión y política. & \\
\hline 42. Clases y desigualdad & 42.Seguridad, conflicto y democratización. & \\
\hline $\begin{array}{l}\text { 43. Ideas, conocimiento y } \\
\text { política }\end{array}$ & 43. Política internacional cuantitativa. & \\
\hline $\begin{array}{l}\text { 44.Pensamiento político } \\
\text { americano }\end{array}$ & 44. Migración y ciudadanía. & \\
\hline \multirow[t]{5}{*}{ 45. Colaboración internacional. } & 45. Relaciones global-local. & \\
\hline & 46. Cultura administrativa & \\
\hline & 47. Socialismo, capitalismo y democracia. & \\
\hline & 48. La política del lenguaje. & \\
\hline & 49. Economía política internacional. & \\
\hline \multicolumn{3}{|c|}{$\begin{array}{l}\text { Fuente: Elaboración del autor con base en: International Political Science Association. Recuperado de: http:// } \\
\text { www.ipsa.org/research-committees/rclist; Asociación Latinoamericana de Ciencia Política, ALACIP. recuperado } \\
\text { de: http://www.congresoalacip2017.org/conteudo/view?ID_CONTEUDO=359, American Political Science } \\
\text { Association. Recuperado de: http://www.apsanet.org/sections }\end{array}$} \\
\hline
\end{tabular}

En los comités y áreas temáticas se incluyen desde el objeto de la disciplina (el poder político), combinaciones temáticas (biología y política; geografía cultural; biopolítica; etnicidad y política; lenguaje y política); campos disciplinares híbridos que también son especialidades disciplinares (sociología política; historia política, comunicación política; sicología política; geopolítica, lenguaje y política; filosofía política); temas específicos múltiples (derechos humanos, sexualidad, inmigración, tecnología y política, educación y política, políticas urbanas) y subcampos de la disciplina (las instituciones, el comportamiento político, las relaciones internacionales, las políticas públicas, la economía política, las organizaciones políticas). También contienen dimensiones metodológicas y la política comparada en diversas temáticas. Esto sin olvidar que dentro de cada temática o área hay múltiples teorías, algunas de ellas en franca confrontación y con postulados contrapuestos, ineludible realidad del pluralismo teórico de todas las ciencias sociales.

Suele ocurrir que las mesas de trabajo de los congresos son propuestas por integrantes de la comunidad académica en convocatorias abiertas y en las cuales da la impresión que se confunde el pluralismo con una muy laxa inclusión de temáticas que corresponde a las líneas de trabajo individual o de grupos, en muchos casos no incluye a politólogos sino a sociólogos, antropólogos, economistas, historiadores y otras disciplinas sociales. Asimismo, en los diversos comités o secciones o grupos de trabajo de las asociaciones hay una enorme multiplicidad de temas y algunos parecen corresponder más a otras disciplinas (como clases sociales, ciudad, inmigración, historia internacional, educación, sexualidad, etnicidad). A la vez que se da una clara especialización en ciertos subcampos y una mayor presencia de campos híbridos, los trabajos de politólogos también circulan en los eventos de varias disciplinas, lo cual se traduce en una ampliación progresiva de las líneas, comités o áreas y se difumina la orientación disciplinar.

Lo anterior es la expresión natural de la profusa comunicación profesional, la mutua influencia de las disciplinas y los trabajos interdisciplinarios. Pero, también es un síntoma de ciertas dinámicas internas en las respectivas comunidades académicas que tienden a sobreponer coordenadas disciplinares no siempre con base en propósitos académicos. 
Son muy frecuentes las convocatorias a eventos con temas genéricos en donde cabe de todo, todas las disciplinas, todas las profesiones, todos los ponentes (desde estudiantes a connotados investigadores, pasando por activistas, políticos, periodistas) y el resultado suele ser la conformación de mesas o paneles con temas y problemas centrífugos que no generan comunicación porque no tienen nexos reales y son producto de arbitrarias agrupaciones (a vece en idiomas diferentes). No es comunicación ni interdisciplinariedad ni un genuino esfuerzo de comprensión multidisciplinar de los problemas políticos.

\section{¿Ordenar el caos disciplinar?}

Es claro que hay una dinámica expansiva que incluye cada vez más temáticas y que revela que la disciplina se ha abierto a muchos tópicos que han ido emergiendo por la dinámica sociopolítica, por los cambios en las organizaciones y en las instituciones, por la mayor visibilidad de actores sociales que han jalonado la investigación y la reflexión que antes era casi inexistente. Asimismo, la enseñanza de la Ciencia Política presenta una gran variedad de temas, subcampos, autores, teorías, aunque en las universidades de mayor prestigio en América latina tienden a converger en algunas asignaturas más bien "clásicas" que, a su vez, hacen parte de algunos subcampos que se han ido delineando dentro de la disciplina.

En torno a lo anterior, como lo ha enfatizado Pablo Boulcourf (2008) para el caso de Argentina, y que puede ser aplicado en términos generales: "es necesario que los politólogos encargados de la formación de sus pares repiensen el 'qué' y el 'para qué' enseñar. Esto requiere generar consensos dentro de la comunidad científico-académica acerca de cuáles serían las áreas disciplinares, sus posibles prácticas y la articulación con los ámbitos institucionales en los cuales se pueden llevar a cabo". En esta dirección Laitin sugiere algunos caminos para ordenar académicamente este "caos" y propone reagrupar las diversas líneas en seis subcampos, cuatro de ellos sustantivos o fundamentales en la disciplina: (1) teoría política, (2) política comparada, (3) instituciones políticas y (4) relaciones internacionales, otro, (5) que corresponde a la metodología en ciencia política que proporciona herramientas, métodos y técnicas para enfrentar los múltiples problemas incluidos en los subcampos y (6) las políticas públicas, como campo de aplicación a problemas relevantes desde los espacios de decisión. Para él la Ciencia Política debería organizarse en torno a un limitado conjunto de estratégicas situaciones o mecanismos políticos fundamentales que le darían coherencia y evitaría que siga siendo una gran paraguas que cubre muchas y variadas temáticas. Estos subcampos son muy parecidos a los que considera la Enciclopedia Británica en su voz Ciencia Política: política comparada, relaciones internacionales, teoría política, administración pública, estudios constitucionales y leyes, políticas públicas, dentro de política doméstica incluye elecciones, opinión pública, gobiernos locales. Aunque resalta la ausencia del énfasis en las instituciones políticas (incluidas los sistemas electorales) y del comportamiento político, en ambos. También en Canadá se diferencian seis subcampos en la enseñanza e investigación en la disciplina: teoría política normativa o filosofía política, política comparada (instituciones, valores, procesos en diferentes países), administración pública y políticas públicas, economía política, relaciones internacionales, la metodología de la investigación científica de la política, también resalta la ausencia del comportamiento político y de las instituciones políticas (Whitaker, R., 2013).

En América Latina Pablo Alberto Bulcourf y Nelson Dionel Cardozo señalan que en los congresos de la disciplina se pueden detectar algunos acuerdos en la comunidad politológica latinoamericana e internacional en torno a seis campos o áreas de la disciplina: (1) política comparada, (2) políticas públicas, (3) opinión pública, (4) relaciones internacionales, (5) instituciones políticas y (6) teoría política (que incluye no solo las teorías positivas sino también las prescriptivas propias de la filosofía política). Coinciden en cinco subcampos o áreas con Laitin y la Encicclopedia Británica, aunque ellos no consideran la metodología 
como un área independiente (aunque si lo plantean cuando sugieren algunas materias como Estadística, metodologías de investigación, talleres de tesis, horas de investigación) e incluyen la de opinión pública, aunque la describen básicamente como comunicación política (Bulcourf \& Cardozo, 2012).

La reflexión de Laitin (también la de Boulcourf) se orienta a intentar ordenar la disciplina y a demostrar que, a pesar de todo, existe cierta coherencia en toda su dinámica expansiva. Avanzando en esta dirección consideramos que, aunque es cierto que hay un amplio abanico y una gran variedad de líneas de trabajo y de temáticas, se pueden buscar líneas de convergencia, temáticas o, más propiamente, subcampos de la disciplina que tienen en común el objeto de la disciplina, esto es, el poder político socialmente regulado. Si hacemos un pequeño ejercicio y comparamos las áreas tenidas en cuenta en algunos manuales internacionales de la disciplina con textos de amplia circulación entre politólogos y que reúnen a representantes de la disciplina con una larga trayectoria y reconocimiento internacional, y las áreas de las convocatorias a los congresos de IPSA (2016) y de la Asociación latinoamericana de Ciencia Política (ALACIP, 2015) y las secciones de APSA (2016), así como el esquema descriptivo de la Enciclopedia Británica, se observan ciertas confluencias: podemos extraer nueve subcampos en los que hay intersección en las que todas se encuentran: teoría política, instituciones políticas, comportamiento político, políticas públicas, economía política, relaciones internacionales, política comparada política, estudios judiciales y metodología de la ciencia política (ver tabla 2).

Tabla 2

Comparativo de los subcampos de la ciencia política

\begin{tabular}{|c|c|c|c|}
\hline $\begin{array}{l}\text { International Political } \\
\text { Science Association (IPSA) } \\
\text { (2018) }\end{array}$ & $\begin{array}{l}\text { American Political } \\
\text { Science Association } \\
\text { APSA (2018) } \\
\text { Secciones organizadas }\end{array}$ & $\begin{array}{l}\text { The Oxford Handbooks of } \\
\text { Political Science (2009) } \\
\text { Robert E Goodin, Ed. } \\
\text { Oxford University Press. }\end{array}$ & $\begin{array}{l}\text { Asociación } \\
\text { Latinoamericana de } \\
\text { Ciencias Políticas } \\
\text { (ALACIP) Congreso, } 2017 \\
\text { Áreas temáticas }\end{array}$ \\
\hline Teoría política & Teoría política & Teoría política & Teoría política \\
\hline Instituciones políticas & Instituciones políticas & Instituciones políticas & $\begin{array}{l}\text { Instituciones y procesos } \\
\text { políticos }\end{array}$ \\
\hline Comportamiento político & Comportamiento político & Comportamiento político & $\begin{array}{l}\text { Comportamiento } \\
\text { electoral, opinión pública }\end{array}$ \\
\hline Políticas públicas & $\begin{array}{l}\text { Políticas públicas y } \\
\text { administración }\end{array}$ & Políticas públicas & $\begin{array}{l}\text { Estado, administración y } \\
\text { políticas públicas }\end{array}$ \\
\hline Economía política & Economía política & Economía política & Economía política \\
\hline $\begin{array}{l}\text { Relaciones } \\
\text { Internacionales }\end{array}$ & \begin{tabular}{|l} 
Relaciones \\
internacionales
\end{tabular} & $\begin{array}{l}\text { Relaciones } \\
\text { internacionales }\end{array}$ & $\begin{array}{l}\text { Relaciones } \\
\text { internacionales }\end{array}$ \\
\hline Política comparada & $\begin{array}{l}\text { Política } \\
\text { comparada }\end{array}$ & $\begin{array}{l}\text { Política } \\
\text { comparada }\end{array}$ & $\begin{array}{l}\text { Política } \\
\text { comparada }\end{array}$ \\
\hline $\begin{array}{l}\text { Política y estudios } \\
\text { judiciales }\end{array}$ & Leyes y corres & $\begin{array}{l}\text { Política y estudios } \\
\text { judiciales }\end{array}$ & Justicia y política \\
\hline $\begin{array}{l}\text { Metodología en ciencia } \\
\text { política (como una } \\
\text { sección) }\end{array}$ & $\begin{array}{l}\text { La metodología en } \\
\text { ciencia política }\end{array}$ & Metodología política & $\begin{array}{l}\text { Metodología y enseñanza } \\
\text { de la ciencia política }\end{array}$ \\
\hline
\end{tabular}

Fuente: Elaboración del autor con base en las fuentes mencionadas.

Si se hace, a su vez, el ejercicio de agrupar los comités de investigación de IPSA en 2018, se pueden incluir en un 81 por ciento en los subcampos mencionados, aunque algunos de ellos probablemente cabrían en varios subcampos según el tipo de estudio que se proponga hacer, especialmente en política comparada. En el otro 19 por ciento 
encontramos algunos saberes híbridos (aunque también se pueden considerar en algunos casos como especialidades disciplinares) o lo que a mediados del siglo XX Jean Meynaud llamara zonas intersticiales (Meynaud, 1960 [1958]): Sociología Política, Sicología Política, Geopolítica, Comunicación Política, Filosofía Política, Etnicidad y Política, Lenguaje y Política, Religión y Política y Antropología Política. Como lo señala Mattei Dogan, la heterogeneidad de la disciplina se ha nutrido de otras disciplinas creando puentes entre espacios de subespecialización lo cual ha conducido a la hibridación, que no es la expresión de una supuesta interdisciplinariedad (expresión que considera borrosa y poco clara) sino combinación entre fragmentos de ciencias, entre una sección o subcampo de la ciencia política y otra disciplina. De esta dinámica resulta que muchos politólogos no solo se relacionan con sus colegas disciplinares sino también con otros colegas que convergen desde sus disciplinas en el estudio y la investigación de problemas políticos. Un ejemplo de esta hibridación es la Sicología Política, campo en el que caben estudios como la socialización política, la alienación, la teoría del rol, la sicobiografía, el análisis de la personalidad, las actitudes y creencias políticas el análisis tipológico de los líderes políticos, la participación de masas, la insatisfacción política, la identificación política. Ambos, el sicólogo y el politólogo, deben recurrir a conceptos, teorías y herramientas metodológicas de la otra disciplina para abordar este tipo de temas. En este caso la Ciencia Política se nutre de las encuestas, de la medición de actitudes, de la medición sociométrica, del análisis de contenido, del método clínico; mientras que el sicólogo debe recurrir a conceptos de participación política, poder, actores políticos, racionalidad, liderazgos políticos, elites: cada disciplina sola no lo puede lograr de buena forma.

Las restantes temáticas son emergentes, surgidas en las últimas décadas, así como los estudios sobre la disciplina (ver tabla 3). Dentro de la categoría "otras" caben diversos asuntos que son abordados por muchas disciplinas y son de naturaleza compartida y ambigua sobre los cuales la Ciencia Política no ejercería un claro predominio, temas como Mujeres y política en naciones desarrolladas, Política y geografía cultural, Género y política, Fuerzas armadas y sociedad (también en política comparada), Derechos humanos (más cercano a la Filosofía Política) y Tecnología y desarrollo.

Tabla 3

Subcampos y comités de trabajo en International Political Science Association

\begin{tabular}{|l|l|l|}
\hline $\begin{array}{l}\text { Subcampos de la ciencia } \\
\text { política }\end{array}$ & Comités \\
\hline Teoría política & $\begin{array}{l}\text {-Pluralismo sociopolítico } \\
\text {-Calidad de la democracia (también se puede } \\
\text { ubicar en política comparada, instituciones, } \\
\text { comportamiento político. } \\
\text {-Repensando el desarrollo político (también } \\
\text { cabe en política comparada) }\end{array}$ & $\begin{array}{l}\text {-Socialismo, capitalismo y } \\
\text { democracia (también en política } \\
\text { comparada). } \\
\text {-Poder político }\end{array}$ \\
\hline Comportamiento político & $\begin{array}{l}\text {-Elites políticas } \\
\text {-Democracia electrónica } \\
\text {-Socialización política y educación. }\end{array}$ & $\begin{array}{l}\text {-Elecciones, ciudadanos y partidos } \\
\text {-Opinión pública y comunicación } \\
\text {-Opinión pública comparada }\end{array}$ \\
\hline $\begin{array}{l}\text { Instituciones } \\
\text { políticas }\end{array}$ & $\begin{array}{l}\text {-Poder legislativo } \\
\text {-Estado de bienestar y sociedades (también } \\
\text { en políticas públicas) }\end{array}$ & $\begin{array}{l}\text {-Federalismo comparado (también } \\
\text { en política comparada) }\end{array}$ \\
\hline $\begin{array}{l}\text { Políticas } \\
\text { públicas }\end{array}$ & $\begin{array}{l}\text {-Burocracias públicas en sociedades } \\
\text { desarrolladas } \\
\text {-Corrupción política } \\
\text {-Estructura y organización del gobierno } \\
\text { - Políticas públicas comparadas }\end{array}$ & $\begin{array}{l}\text {-Políticas públicas y administración } \\
\text {-Cultura administrativa } \\
\text {-Opinión pública y administración }\end{array}$ \\
\hline
\end{tabular}




\begin{tabular}{|l|l|l|}
\hline $\begin{array}{l}\text { Relaciones } \\
\text { internacionales }\end{array}$ & $\begin{array}{l}\text {-Unificación europea } \\
\text {-Nuevo Orden mundial } \\
\text {-Geopolítica } \\
\text {-Sistema de integración y naciones divididas }\end{array}$ & $\begin{array}{l}\text {-Política cuantitativa internacional } \\
\text {-Relaciones global-local } \\
\text {-Género, globalización y democracia }\end{array}$ \\
\hline Economía política & -Política y negocios & \\
\hline $\begin{array}{l}\text { Política } \\
\text { comparada }\end{array}$ & $\begin{array}{l}\text {-Estudios comparados de gobiernos locales } \\
\text {-Estudios judiciales comparados } \\
\text {-Democratización en perspectiva comparada }\end{array}$ & $\begin{array}{l}\text {-Estudios de Asia y del Pacífico } \\
\text {-Políticas comparas en salud } \\
\text {-El papel de los militares en la } \\
\text { democratización }\end{array}$ \\
\hline $\begin{array}{l}\text { Metodología } \\
\text { Política }\end{array}$ & $\begin{array}{l}\text { - Conceptos y métodos } \\
\text {-La ciencia política como disciplina }\end{array}$ & \\
\hline $\begin{array}{l}\text { Saberes } \\
\text { híbridos }\end{array}$ & $\begin{array}{l}\text {-Sociología política } \\
\text {-Biología y política } \\
\text {-Comunicación política } \\
\text {-Psicología política }\end{array}$ & $\begin{array}{l}\text {-Geopolítica } \\
\text {-Religión y Política } \\
\text {-Lenguaje y política } \\
\text {-Política y etnicidad }\end{array}$ \\
\hline $\begin{array}{l}\text { Otras líneas } \\
\text { temáticas }\end{array}$ & $\begin{array}{l}\text {-Ciencia y política } \\
\text {-Mujeres y política en naciones desarrolladas } \\
\text {-Política y geografía cultural }\end{array}$ & $\begin{array}{l}\text {-Género y política } \\
\text {-Fuerzas armadas y sociedad } \\
\text { (también en política comparada) } \\
\text {-Derechos humanos } \\
\text {-Tecnología y desarrollo }\end{array}$ \\
\hline Fuente: Elaboración propia con base en http://www.ipsa.org/research-committees/rclist \\
\hline
\end{tabular}

De forma breve podemos definir cada subcampo en los siguientes términos. La teoría política se refiere a las dilucidaciones conceptuales, los modelos y explicaciones del origen y la naturaleza de los hechos políticos. Se advierte una distinción entre las teorías políticas normativas o prescriptivas (propias de la filosofía política que se ocupan del deber ser, del estado óptimo, de la buena república) y las teorías políticas positivas, de índole empírico analítico, aquellas "especulaciones razonadas y precisas sobre la respuesta que cabe dar a las preguntas de una investigación" (King, Keohane, \& Verba, 2000), o, en términos de Karl Popper, como hipótesis o conjunto de hipótesis, como solución propuesta a un problema de investigación que debe ser sometida a un procesos de contrastación. Al respecto es muy clara la distinción de Dieter Nohlen quien considera tres elementos propios de este tipo de teorías: (a) son sistemas de afirmaciones fundadas o bien hipótesis generalizadas sobre ciertos hechos, acciones, sus relaciones entre sí y sobre las causas, estructuras y regularidades que subyacen a estos; (b) contienen afirmaciones sobre las precondiciones/ condiciones marginales en las cuales se pretende que las afirmaciones tengan validez $y$, (c) pretender tener carácter explicativo y capacidad de pronóstico, deben poder explicar las circunstancias de sus respectivo objeto y permitir que se hagan afirmaciones sobre eventuales modificaciones y se formulen hipótesis sobre circunstancias nuevas aun no conocidas (Nohlen, 2012).

En ciencia política existen teorías de la democracia, del Estado, de los conflictos, de las revoluciones, de la acción colectiva, del poder político, de las instituciones, del comportamiento político, de las relaciones internacionales, de los partidos, de las elites, entre muchas otras. De igual forma que en las demás ciencias sociales, hay una pluralidad de teorías que pueden ser opuestas en sus presupuestos y conceptos y suelen entrar en disputas sobre su mayor capacidad explicativa. Esto lo sintetizó Gabriel Almond (1988) en su muy recurrida expresión de "mesa separadas". En todo caso, se trata de teorías fundadas en la contrastación y que no tienen pretensiones generales, son teorías de alcance intermedio, cuyas generalizaciones son contextualizadas, sectoriales, temáticas y, por supuesto, siempre sujetas a revisión. Desde el planteamiento inicial de Robert Merton estas teorías se proponen dar cuenta de aspectos o esferas demarcadas de la realidad a diferencia de las teorías con pretensiones totalizantes, la gran teoría que incluso algunos denominaron "paradigmas". Aunque no pretender validez general ni proponen generalizaciones de 
amplio rango, tampoco se limitan a describir o a dar cuenta de hechos aislados y proponen enunciados con un rango y un alcance medio, contextual y siempre permiten alguna forma de verificación y de prueba empírica. (Boudon, 1991); (Hedström \& Udehn, 2009).

El subcampo del comportamiento político se refiere a las diversas formas de participación social, ciudadana, comunitaria y política, dentro de esta última, la participación electoral, que ha constituido uno de los temas de más tradición en la Ciencia Política desde las primeras décadas del siglo XX con el impulso inicial en Francia y posteriormente por el conductismo desde Estados Unidos. Se refiere a las actitudes, al pensamiento y las conductas en los procesos políticos, incluye también el estudio del comportamiento de las dirigencias políticas, de los legisladores, de las elites y de la clase política en tanto entran en relaciones en las esferas del poder político, también los estudios de opinión pública desde diversos enfoques, entre ellos las encuestas y sondeos que suelen ser cobijados bajo la denominación de "cultura política". En un sentido amplio también se incluyen a los partidos como organizaciones que canalizan las candidaturas y la participación, a los gremios y asociaciones que actúan como actores relevantes que pretenden incidir en la toma de decisiones. Aunque en sus comienzos estuvo muy ligado a la sicología y a la sociología, en sus posteriores desarrollos se fue configurando como un campo politológico claramente demarcado, cada vez más formalista y sofisticado con base en la apropiación de herramientas metodológicas de la estadística y la economía y se han desarrollado algunas herramientas y métodos analíticos, así como diversos índices utilizados cada vez con más frecuencia en estudios comparados que recurren a modelos sofisticados. Suele incluirse dentro de este subcampo también la comunicación política y el marketing electoral, cuyo propósito es el de investigar, planear y ejecutar acciones orientadas a la población a favor de un candidato y/o partido, asimismo los estudios sobre el capital social y si incidencia en los patrones de participación y desarrollo de la democracia.

El subcampo de las instituciones políticas, esto es, las reglas de juego, las normas y caminos pautados que regulan las conductas de los actores políticos individuales y colectivos, se ha convertido en uno de los principales subcampos de la ciencia política. Desde comienzos de la década de 1980 las instituciones se convirtieron de nuevo en uno de los objetos centrales del estudio de la política con la emergencia de las diversas corrientes que han sido denominadas como nuevo institucionalismo, se considera como la obra que redimensiona el estudio de las instituciones el artículo de (March \& Olsen, 1984), que luego se convirtió en el libro (March \& Olsen, 1989), de tal forma que se habla de una tercera revolución al interior de la Ciencia Política tras las dos precedentes del conductismo y de la teoría de la elección racional.

Si bien desde décadas anteriores la Ciencia Política se ocupó del estudio de las constituciones, de las estructuras formales-legales de los Estados y sus estructuras organizaciones y funcionales, con el neoinstitucionalismo adquieren relevancia y se posiciona en un primer plano el papel de las instituciones, de las reglas de juego (North, 1993); de los caminos pautados de acción en el estudio de los regímenes políticos (presidencialismo, parlamentarismo y formas mixtas), de los sistemas electorales y su incidencia en los sistemas de partidos, en los partidos, de la participación, en la actuación de las elites y de los dirigentes políticos; del Congreso y las legislaturas; de las relaciones entre poderes; de los diseños funcionales y territoriales del Estado y de una amplia gama de temas y problemas políticos. Por su gran influencia en la Ciencia Política, que ha llevado a que se incorpore el papel de las instituciones en el estudio de lo político, Pierson y Skocpol (2008) Ilegaron a plantear que "todos somos neoinstitucionalistas", es decir, que más allá del papel que se le asigne a las instituciones y la forma como estas se definan, no podemos olvidar su importancia, el papel que estas juegan en la dinámica socio-política. No obstante, como ocurre en todos los subcampos de la disciplina, el pluralismo teórico aquí se expresa en varias 
versiones del neo institucionalismo: histórico, sociológico, cultural, contextualizado y de la teoría de la elección racional. El abanico va desde las visiones más deterministas que consideran que las instituciones constituyen la principal y fundamental variable para explicar los hechos políticos, hasta quienes señalan que las instituciones solo son una variable más y que es necesario considerar factores de contexto o las trayectorias históricas. Como lo sintetizan (Hall \& Taylor, 1996); (Guy, 2001); (Guy Peters, 2003).

Hay numerosos estudios fundados en estas perspectivas y el abanico de temas incluye desde los regímenes políticos (presidencialismo, parlamentarismo), las elecciones, los partidos políticos, las conductas, las elites, las legislaturas, los gobiernos locales, la corrupción, entre muchos otros.

Por su parte, las políticas públicas abordan los procesos de formulación, implementación, ejecución, seguimiento y evaluación de las políticas surgidas desde el Estado en sus diferentes niveles territoriales, así como las que son producto de las relaciones entre lo público y lo privado. Con el surgimiento de las políticas sociales desde el último cuarto del siglo XIX y la posterior asunción de obligaciones de cohesión social, de regulación y de funcionalidad del Estado como actor que cada vez se orienta a una mayor racionalidad en sus acciones adquiere relevancia el estudio de esas acciones, así como una dimensión de aplicación. El estudio de los problemas y las políticas públicas tiene los antecedentes más claros también en Estados Unidos a comienzos de la década de 1950 y desde entonces se ha desarrollado y sofisticado. Se trata de un subcampo que tiene la especificidad de orientarse a la solución de problemas, tiene una doble dimensión teórica y práctica y en las últimas dos décadas han adquirido relevancia las denominadas Think Thanks, centros de pensamiento que cada vez tienen mayor influencia en las políticas y el manejo de lo público. Este constituye un subcampo disputado y/o compartido con la Economía y la Administración Pública. Como lo recuerda Bárbara J. Nelson (1996), surgió especialmente en Estados Unidos después de la segunda posguerra. Aunque en Francia e Inglaterra se desarrollaron estudios sobre el Estado y el gobierno es en Estados Unidos en donde tomará un mayor impulso lo cual se explica en gran medida por el imperativo de pensar en la gestión y en la eficiencia de las acciones estatales tras la guerra que había destruido a Europa. Se ampliaron los temas de estudio sobre la gestión, las decisiones, la planeación, la acción gubernamental, su seguimiento y evaluación. Este subcampo está asociado de forma muy acentuada al quehacer político, a la intervención desde la esfera política y gubernamental para resolver situaciones y problemas colectivos. Se fomentó la investigación y la reflexión sobres nuevas tendencias y formas de gobernar de manera eficaz y eficientemente. El enfoque científico de las políticas ganó espacio, aunque de forma tardía, lo cual se registra en el hecho de solo en 1983 se creó en la Asociación Americana de Ciencia Política esta área de trabajo.

En cuanto a la economía política, este es un subcampo de confluencia de la economía y la ciencia política que ha ido ganando espacio y que corresponde a la relación entre las instituciones y los incentivos y estrategias que hacen que los individuos se comporten de formas determinadas y la forma como estas instituciones afectan el funcionamiento del sistema económico. A diferencia de lo que ocurría con esta denominación desde el siglo XIX, cuando se asociaba la política a la economía asumiéndolos como intercambiables o asociándose al pensamiento social y filosófico, en las últimas décadas se ha modificado su sentido con énfasis en el contexto político en el cual se llevan a cabo los fenómenos económicos, modelos sobre el comportamiento del gobierno en términos de racionalidad económica, la política económica, las relaciones entre el mercado y la democracia, los modelos de funcionamiento económico del Estado. En un sentido básico se trata, como lo sintetizan James E. Alt y Alberto Alesina (2001) se refieren a las investigaciones que intentan responder a dos cuestione centrales: ¿cómo evolucionan las instituciones en respuesta 
a los incentivos, estrategias y elecciones individuales?, y ¿cómo afectan las instituciones a funcionamiento de los sistemas político y económico? En cuanto a su forma de abordar, se trata de un enfoque económico que recurre al comportamiento estratégico y maximizador de los agentes para explicar los orígenes y el mantenimiento de las instituciones y procesos políticos y la formulación e implementación de políticas públicas. Incluye temáticas como El análisis micro y macro económico; Economía estática y economía dinámica; Relación entre Economía, Derecho y Política; el sistema económico y la estructura jurídico política; las instituciones jurídicas y económicas del sistema capitalista; la visión económica de las constituciones; las leyes económicas y su relación con la organización jurídica; los regímenes del mercado de competencia perfecta e imperfecta.

Las relaciones internacionales se asumen de tres formas diferentes: como una disciplina autónoma; como un campo transdisciplinar en el que convergen la Ciencia Política (CP), la Economía, la Sociología, el Derecho Comparado; o como subcampo de la Ciencia Política.

Por ejemplo, Sarquís asume que se trata de una disciplina autónoma, pero que tiene deudas con otras disciplinas sociales, de las cuales se diferencia: "se ha hecho el reconocimiento explícito de! adeudo de nuestra disciplina específicamente con la ciencia política, el derecho, la filosofía, la sociología y la historia, al punto que algunas de ellas todavía reclaman el estudio de las relaciones internacionales como patrimonio propio [....]nuestra disciplina comparte problemas, especialmente de carácter epistemológico y metodológico con el resto de las ciencias sociales y se puede beneficiar con amplitud del camino recorrido por todas ellas, tal y como se nutre el desarrollo general de la ciencia a partir de sus experiencias particulares en cada una de sus ramas, pero no es necesario "meter a la batidora" porciones de todas las demás disciplinas. Aunque reconoce que se trata de una disciplina aun en procedo de construcción como saber autónomo. sociales o de su experiencia epistemológica, para extraer de ahí el conocimiento de lo internacional. Aunque suene reiterativo, es fundamental, en cambio, reconocer que lo internacional como objeto de estudio es un ámbito fenomenológico diferenciado y de mayor complejidad que el ámbito local en el que tradicionalmente se habían desarrollado el resto de las disciplinas sociales (Sarquís, David J, op.cit).

En este último sentido se asume en esta propuesta, considerando que, a diferencia de los demás subcampos, este tiene una mayor tradición, al punto que algunos lo consideran "una disciplina dentro de una disciplina". Este punto de vista no desconoce la peculiaridad de las RI pues, a la vez que se reconoce como un subcampo de la CP, también considera la confluencia multidisciplinar, especialmente desde finales de la década de 1970 (Ashworth, 2009). En todo caso se trata de fronteras difusas que se expresan en las ofertas formativas que con frecuencia se hacen de forma autónoma considerando las relaciones internacionales como una disciplina y una profesión autónoma; en otros casos se le agrega a la ciencia política las relaciones internacionales considerándolas inseparables, o al menos anunciando un énfasis, y en otros se incluye como un componente de las mallas curriculares de la ciencia política de tal forma que el politólogo debe formarse al menos en sus fundamentos teóricos y metodológicos.

Se trata de un debate abierto frente al cual consideramos que en el pregrado el politólogo debe contar con una formación inicial básica en relaciones internacionales abordando el estudio de los problemas centrales de índole político del sistema internacional: las relaciones entre estados; los conflictos; globalización, integración regional; gobernabilidad internacional; las organizaciones y la política internacionales; la economía política internacional; la diplomacia; el manejo estratégico de los recursos; la geopolítica de los recursos, entre otros. Con antecedentes en la Historia de los Tratados y en la Historia Diplomática y a diferencia de otros subcampos que surgieron y se consolidaron en Estados Unidos, 
las relaciones internacionales se institucionalizaron de forma temprana en Europa desde las primeras décadas del siglo XX y posteriormente se empezó a desarrollar en Estados Unidos de forma progresiva y expansiva, especialmente en la segunda postguerra. Debido a las transformaciones y convulsiones de las dos últimas décadas sus teorías han sido debatidas de forma amplia en la comunidad politológica.

La política comparada. Como se ha referenciado tantas veces, las comparaciones en el estudio político tienen antecedentes en la antigüedad en la Grecia clásica y Aristóteles es uno de los pioneros remotos cuando incursionó en el análisis comparado de las constituciones de los estados y adelantó clasificaciones. No obstante, una cosa son los análisis comparados antes de que existiera la ciencia política como disciplina autónoma y otra cosa es su constitución en el núcleo metodológico al interior de la disciplina. La política comparada emergió en Estados Unidos en el contexto de la segunda postguerra tras los procesos de descolonización que hicieron más "visibles" a otras sociedades diferentes a las europeas y norteamericana, a nuevos estados, a nuevas realidades con lo que se evidenció la necesidad de nuevos conocimientos y nuevas formas de estudiar la realidad social. Se asume como un método que consiste en el procedimiento sistemático orientado a extraer generalizaciones empíricamente contrastables mediante el estudio de dos o más casos.

Constituye uno de los métodos de control que se propone explicar regularidades acudiendo al estudio de un número importante de casos y en las últimas décadas se han multiplicado los estudios comparados con metodologías, fuentes y técnicas renovadas. Como lo señala Peter Mair, se puede considerar que la política compara se compone de tres elementos que, a su vez, permiten diferenciar tres momentos de su desarrollo: pensada como el estudio de países extranjeros, que en realidad involucra escasa comparación; como la comparación sistemática entre países para identificar y explicar las diferencias o similitudes entre ellos en el aspecto específico que se esté analizando, se trata de elaborar teorías y comprobarlas y los países constituyen los casos; y como método de investigación se centra en las reglas del desarrollo y en los estándares sobre la mejor forma de llevar a cabo la investigación comparada, incluyendo los niveles de análisis, sus límites y posibilidades (Mair, 2001). Son cada vez más numerosos y cualificados los trabajos basados en la comparación e incluyen las democracias, los sistemas electorales, la opinión y los valores políticos, las elecciones, las transiciones, la democratización, la acción colectiva, la corrupción, el cambio político y un largo etcétera.

Respecto a la metodología de la Ciencia Política, más que un subcampo, en ella encontramos las estrategias de investigación y las herramientas de las cuales se hace uso en la investigación politológica. Haciendo acopia y tomando prestados los aportes de otras ciencias sociales (la sociología, la antropología, la sicología, la economía) la disciplina recurre a métodos cualitativos como análisis de casos con una variable explicativa, múltiples casos con variables diversas, estudios de caso en profundidad, entrevistas, análisis documentales, análisis del discurso. Pero también a métodos cuantitativos y en las últimas dos décadas ha recurrido de forma recurrente (y predominante en Estados Unidos) a la econometría, a la construcción de modelos de carácter multivariados, a modelos de la estadística inferencial y a metodología experimental Se mantiene viva la controversia comprensión-explicación, a la vez que han surgido debates respecto a la cuantificación consideradas por algunos fundamental y por otros sólo una alternativa metodológica, entre otras, y la defensa y controversia de las interpretaciones que puede conducir a descripciones subjetivas y a la pretensión de validación de todo tipo de interpretaciones sin ajuste a orientaciones básicas de rigor conceptual y metodológico. La especulación disfrazada de pensamiento crítico (Alarcón Olguín, 2006); (Alker, 1996).

Se ha planteado que la adopción, al "tomar prestados" métodos y herramientas metodológicas de otras disciplinas ha generado un cierto sentido de inautenticidad disciplinar 
entre los politólogos frente a otras disciplinas. Frente a ello puede considerarse que la Ciencia Política incorpora los aportes de otras disciplinas, algunos los adecuan y perfecciona y genera también sus propias herramientas. Al respecto es pertinente la afirmación de Hayward R. Alker: "tenemos derecho a usar todo lo que sea útil para nuestras preocupaciones sustantivas y nuestros propósitos metodológicos entre docenas de posibilidades relevantes en la literatura inferencial y figurativa. Esto en la búsqueda de conocimiento que se exprese de forma lógica, coherente, con evidencias adecuadas, de forma pública y transparente.

\section{¿Formación mínima profesional?}

A la luz de lo expresado en los apartados anteriores: ¿se puede plantear que hay un cuerpo de conocimientos, de subcampos o líneas o áreas que podrían considerarse como estándares y universales para la formación de politólogos?

Al plantear esta cuestión se parte de dos ideas básicas de Robert Goodin y HansDieter Klingemann: en el proceso formativo existe un marco disciplinar y se presume una formación mínima profesional. En cualquier disciplina los nuevos miembros, quienes se están formando en su campo y aspiran a ingresar a la comunidad académica, se socializan en autores, problemas, tópicos, temáticas, teorías, conceptos, metodologías, técnicas, ciertas pautas y normas que sirven de base para la evaluación de los integrantes de la comunidad respectiva entre sí, para que los pares cuenten con criterios de valoración y discusión de las publicaciones, del trabajo investigativo, de la participación en la esfera pública y en los eventos académicos. Asimismo, estas pautas y normas constituyen los criterios con los cuales se accede a un lugar en las universidades, institutos y centros de investigación. Este planteamiento relaciona las dos ideas con algunos textos centrales de autores clásicos, incluidos los "clásicos instantáneos" (aquellos autores cuyas obras irrumpen en la comunidad académica y tienen un gran impacto en una o varias subáreas) y con temas recurrentes que aparecen siempre en los programas curriculares, en los eventos internacionales y en publicaciones e amplia circulación entre politólogos. Esta propuesta supone la presencia de ejes centrales que podrían contener los mapas curriculares en la formación de pregrado/licenciatura/grado con tres componentes básicos: un núcleo disciplinar; los saberes híbridos (para algunas subdisciplinas) y los temas emergentes o nuevas voces que se van abriendo campo en la disciplina.

Puede ser razonable considerar que las ocho áreas, secciones o subcampos que resultan de las intersecciones entre las asociaciones internacionales de la disciplina y los citados Handbook sirven de coordenadas o elementos centrales en los cuales deberían formarse los politólogos en un mundo globalizado en el que hay un imperativo de la interacción y la comunicación frecuente, además de los autores clásicos y de una bibliografía de referencia a la manera de lo que señalaba Norberto Bobbio, de los "autores que cuentan". En primer lugar, se puede hacer una lista provisional, tentativa e ilustrativa sobre posibles espacios formativos dentro de cada uno de los nueve subcampos que incluyen la formación teórica, los conceptos, las metodologías y herramientas técnicas de la disciplina y de otras disciplinas que son adoptadas y/o prestadas, como ocurre en la interacción y mutuas influencias entre las disciplinas sociales. Es solo ilustrativo, no es exhaustivo. En segundo lugar, se mencionan algunos saberes híbridos que también resultan de las intersecciones señaladas y que constituyen espacios de trabajo colaborativo disciplinar en el que convergen la politología, la historia, la sociología, la economía, la sicología. En tercer lugar, están los temas nuevos en los que han incursionado politólogos y que están presentes en los debates, en los eventos y en las publicaciones especializadas. También se trata solo de un ejercicio ilustrativo. 
Al considerar que existe un núcleo disciplinar -que se convierte también en núcleo profesional y que suele denominarse también campo de fundamentación disciplinar- se asume que es fácilmente homologable un título que se expida en la disciplina en un país europeo, o en Estados Unidos o en América Latina -con las correspondientes variaciones en contenidos curriculares y en las bibliografías que cada institución y cada cuerpo de profesores prefieren en la formación de sus estudiantes-. En este sentido, tanto el conjunto de los programas como las etiquetas, o denominaciones de los cursos incluidos en los programas formativos tienen referentes comunes en temas, conceptos, teorías, metodologías, autores, libros y artículos, de tal forma que quienes son portadores del título de politólogo manejan ciertos códigos, un lenguaje común que les permite el intercambio y la comunicación con sus colegas, independientemente de donde se han formado. Esto, por supuesto, no significa que la formación debe ser estandarizada pues no se trata de una producción en serie y mecanizada de politólogos, pero si supone que haya ciertos acuerdos formativos implícitos, que cuando se hable en los eventos académicos internacionales, por ejemplo, de instituciones, de sistemas electorales, de democracia, de partidos, de conflictos, de políticas públicas, de clientelismo, quienes participan del diálogo tengan coordenadas en común, así expresen -como es de esperar- preferencias temáticas, enfoques y metodologías diferentes.

En la práctica esto viene ocurriendo en las últimas décadas. Cada vez son mayores los intercambios académicos de estudiantes, las estancias de investigación, la formación doctoral y en maestrías de latinoamericanos en Europa y en Estados Unidos, también es mayor el intercambio en sentido contrario, hay muchos investigadores europeos y de Estados Unidos que son o han sido profesores visitantes en América Latina y son también numerosos los casos de latinoamericanos que ejercen de profesores en este país. El flujo de intercambios es cada vez mayor, así como el debate de ideas y esto se refleja en la construcción o en las reformas de mallas curriculares de los pregrados que se alimentan de las mutuas influencias. Cuando se va a diseñar un programa de pregrado en cualquier país se cuenta con decenas de programas de todo el mundo a la mano para estudiarlos, compararlos y extraer de ellos saberes, experiencias y tradiciones que hacen que no se parta de cero. Igual sucede con el diseño de programas de asignaturas, hay todo un mundo abierto para pensar y proponer cursos que estén inmersos en los términos que maneja la comunidad académica. Este flujo de intercambios virtuales o directos va generando convergencias, puntos de encuentro, acuerdos implícitos o explícitos, muchos de los cuales se reflejan en los diseños curriculares y sucede no solo con el núcleo disciplinar, también con los campos híbridos, que se han ido consolidando en las últimas décadas.

Los temas emergentes, las nuevas voces, son numerosas y dependen mucho de la singularidad de intereses y de oportunidades que haya en cada caso. Aunque hay algunas temáticas que son más recurrentes que otras -como los estudios de género y política; educación y política; medio ambiente y políticas públicas; intelectuales y política- hay otras con menor desarrollo y que son menos extendidas, algunas son de muy reciente aparición y son muy embrionarias -como la democracia electrónica, los movimientos sociales virtuales. En las mallas curriculares suelen ocupar espacios de asignaturas electivas u optativas, según las preferencias y orientaciones de los estudiantes. También tienen su lugar y son importantes, pero diferenciadas del núcleo disciplinar. 
Tabla 4

Esquema indicativo para la construcción de malla curricular en la formación de politólogos

\begin{tabular}{|c|c|c|c|}
\hline \multicolumn{4}{|c|}{$\begin{array}{l}\text { Subcampos } \\
\text { disciplinares y núcleo formativo (ejemplos de temas para asignaturas) }\end{array}$} \\
\hline 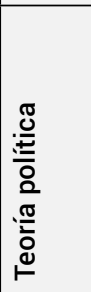 & $\begin{array}{l}\text {-Teorías políticas positivas } \\
\text {-Teorías del Estado } \\
\text {-Teorías de la democracia } \\
\text {-Teorías del conflicto } \\
\text {-Teorías del poder } \\
\text {-Teoría de las elites } \\
\text {-Teorías del comportamiento político. }\end{array}$ & 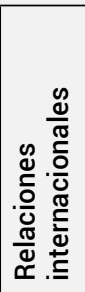 & $\begin{array}{l}\text {-Política exterior y nuevo orden } \\
\text {-Teoría de las relaciones internacionales. } \\
\text {-Conflictos internacionales } \\
\text { - Seguridad internacional y control de armas } \\
\text {-Sistemas de integración } \\
\text {-Estudios de Asia y del Pacífico } \\
\text {-Globalización y economía. }\end{array}$ \\
\hline 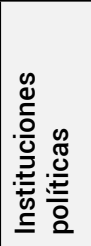 & $\begin{array}{l}\text {-Sistemas electorales y partidos } \\
\text { políticos } \\
\text {-Federalismo y centralismo } \\
\text {-Regímenes constitucionales } \\
\text {-Teorías neoinstitucionales } \\
\text {-Presidencialismo y parlamentarismo }\end{array}$ & 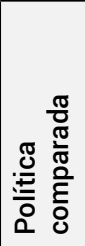 & $\begin{array}{l}\text {-Sistemas políticos } \\
\text {-Partidos políticos } \\
\text {-Democratización } \\
\text {-Transiciones políticas } \\
\text {-Transiciones a la democracia } \\
\text {-Revoluciones y conflictos sociales } \\
\text {-Sistemas electorales y de partidos. }\end{array}$ \\
\hline 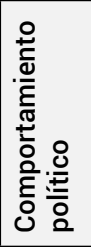 & $\begin{array}{l}\text {-Elecciones } \\
\text {-Opinión pública } \\
\text {-Movimientos sociales } \\
\text {-Partidos políticos } \\
\text {-Socialización política } \\
\text {-Clase política y liderazgo }\end{array}$ & 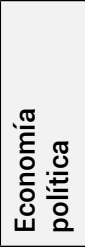 & $\begin{array}{l}\text {-Teorías económicas } \\
\text {-Elección pública } \\
\text {-Capitalismo y democracia } \\
\text {-Bases económicas de la política }\end{array}$ \\
\hline 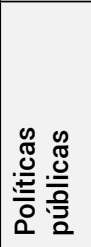 & $\begin{array}{l}\text {-Formulación de políticas } \\
\text {-Políticas públicas locales } \\
\text {-Reformas del Estado } \\
\text {-Gestión pública } \\
\text {-Burocracias públicas } \\
\text {-Administración pública } \\
\text {-Políticas públicas de género }\end{array}$ & 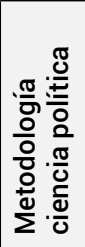 & $\begin{array}{l}\text {-Epistemología de las ciencias sociales } \\
\text {-Métodos cualitativos } \\
\text {-Matemáticas y ciencia política } \\
\text {-Estadística inferencial } \\
\text {-Métodos experimentales }\end{array}$ \\
\hline
\end{tabular}

\begin{tabular}{|l|l|l|}
\hline Saberes convergentes & \multicolumn{2}{|l|}{ Algunas temáticas emergentes opcionales/optativas } \\
\hline -Historia política (nacionales, de Europa, de & -Militares y regímenes & -Ciencia, tecnología y política. \\
América Latina). & -Ciencia y política & -Política y medio ambiente \\
-Sicología política & -Educación y política & -Redes políticas \\
-Antropología política & -Descentralización y política & -Ideas, conocimiento y política. \\
-Sociología política & -Derechos humanos & -Intelectuales y política \\
-Religión y política & -Política y cine & -Individuo y comunidad \\
-Biología y política & -Literatura y cine & \\
-Comunicación política & -Género y política \\
-Etnicidad y política & -Nación y guerra & \\
-Lenguaje y política & & \\
-Política y estudios judiciales & & \\
\hline Fuente: elaboración propia. & & \\
\hline
\end{tabular}

En síntesis: frente a la proliferación y expansión de tópicos, temas y problemas de los cuales se ocupan los politólogos, rastreados en la bibliografía especializada, en los eventos internacionales principales, en publicaciones de alta circulación y referencia y en la variedad de las mallas curriculares de los programas universitarios en los que se forman politólogos, se puede plantear que ante el aparente caos disciplinar es razonable formular una propuesta que contenga criterios generales para la formación del politólogo (en pregrado, grado o licenciatura) con base en las nociones de marcos disciplinares y formación mínima profesional. Sin ánimos de estandarizar ni de unificar la formación de los politólogos (lo 
cual sería insólito y pretencioso), pero con el interés de sugerir posibles marcos generales que constituyan un núcleo formativo común, este texto recupera planteamientos de otros politólogos y reordena y amplía un esquema general para la discusión.

\section{Conclusiones}

Este artículo ha planteado algunas consideraciones sobre la formación de los politólogos; sobre áreas, líneas y subcampos formativos que pueden considerarse propios de su núcleo duro y si es válido hablar de una formación mínima profesional del politólogo.

El argumento considera que existen diversas concepciones acerca del objeto, diversos enfoques y teorías y un aparente caos disciplinar, pero la disciplina ha ido encontrando y construyendo ciertos acuerdos que se manifiestan en una orientación mayoritaria a considerar el objeto centrado en el poder político, en algunos subcampos y temáticas comunes en los eventos internacionales de la disciplina, en un cuerpo de conocimientos y de autores considerados centrales y que son recurrentemente referenciados en las investigaciones y las publicaciones. A través de la búsqueda de intersecciones en los eventos internacionales cruzados con las temáticas de uno de los recientes Handbook de la disciplina y planteamientos de diversos politólogos se proponen ocho subcampos disciplinares y una variedad de temáticas dentro de estos que podrían ser considerados como núcleo formativo disciplinar en el nivel de pregrado o licenciatura, esto es, las áreas y los tópicos que debería conocer un politólogo como mínimo, algunos con mayor profundidad que otros, pero con un panorama de acercamiento a todos ellos, sus problemas centrales, autores y libros o artículos que son referentes. Dentro de esto núcleo se encuentra la metodología de investigación que tiene un carácter transversal y que no solo toma prestadas herramientas de otras disciplinas, sino que también ha avanzado en sus propias construcciones y diseños, como la política comparada (que es a la vez un subcampo y una metodología) y algunos diseños experimentales y de simulación.

Se propone complementar el núcleo central con los saberes híbridos y las temáticas emergentes, estos dos últimos se pueden manejar en el diseño curricular como espacios optativos según las preferencias de los estudiantes y/o los propósitos formativos de los programas cuando se estructuran con énfasis. Esta es básicamente la conclusión del artículo como respuesta a posibles tendencias expansivas y centrífugas en la disciplina. Es una forma de ordenar y de conjugar los subcampos disciplinares internos con los aportes de otras disciplinas y los tópicos que han ido ganando espacio e interés entre los politólogos evitando que se convierta en una cach-all social science en donde cabe de todo y todos. Aunque se acepta la importancia de la interdisciplinariedad es fundamental que cada disciplina se construya con referentes claros acerca de las parcelas de la realidad de las que se ocupa. De nuevo, bajo la premisa del pluralismo teórico, pero defendiendo el legado que le han dejado a la disciplina aquellos países en donde esta se ha institucionalizado más temprano y han aportado teorías, conceptos, herramientas metodológicas, Europa occidental y Estados Unidos.

Se resalta que un cuerpo de conocimientos mínimos compartidos es importante para el trabajo del politólogo. Hay que reiterarlo: no se propone homogenizar la formación del politólogo ni se defiende la existencia de un supuesto diseño curricular ideal universal, solo se sugieren algunos criterios que podrían constituirse en orientaciones o sugerencias para la formación en la disciplina en el nivel básico. Quedan, en todo caso una serie de cuestiones acerca de la formación básica de los politólogos: lo que leen los estudiantes de Ciencia Política; los diseños y herramientas metodológicas más recurridas, pertinentes y relevantes en las investigaciones; los autores que circulan de forma amplia en los micro-currículos; los autores más citados en cada subcampo; los debates epistemológicos recurrentes, entre otras. 
La profesión en la actualidad tiende a globalizarse, a regirse por estándares internacionales y el mercado es cada vez más trasnacional, de tal forma que reivindicar una formación que invoque realidades locales y provinciales y rechace los aportes a la disciplina que proviene de otros países no tiene sentido.

\section{Referencias bibliográficas}

Alarcón Olguín, V. (2006). La importancia del método para el análisis político. En Metodología para el análisis político. México: Universidad Autónoma Metropolitana.

Alker, H. (1996). La metodología en Ciencia Política: lo Viejo y lo Nuevo. En R. E. Goodin, \& H.-D. Klingemann. Madrid, España: Istmo.

Almond, G. (1988). Mesas separadas: escuelas y corrientes en las ciencias políticas. En Una disciplina segmentada. Escuelas y corrientes en Ciencia Política. México: Fondo de Cultura Económica.

Almond, G. (1988). Separate Tables: Schools and Sects in Political Science en PS: Political Science \& Politics. Denton: American Political Science Association Vol. $21, N^{\circ} 4$.

Ashworth, L. (2009). Interdisciplinary and International Relations. European Political Science, núm. 8, 16-25.

Azpuru, D. (2005). La ciencia política en Guatemala: el reto de la consolidación como disciplina independiente. Ciencia Política, Vol. 25 No. 1, 171-181.

Boudon, R. (1991). What Middle-range theories. Contemporary Sociology, American Sociological Association, 20 (4), 519-522.

Boulcourf, P. (2008). Algunas reflexiones sobre la enseñanza de la Ciencia Política en Argentin. Postdata No 13.

Bulcourf, P. A. (2012). El desarrollo de la ciencia política en Argentina. Ciencia Política Vol.50, N0. 1, 59-92.

Bulcourf, P. A., \& Cardozo, N. D. (2012). La enseñanza de la ciencia política en las universidades latinoamericanas: apuntes para una agenda de desarrollo, Universidades, año LXII. Nueva época No 53.

Bulcourf, P., \& Cardozo, N. (2011). La fábrica de politólogos: la enseñanza de la ciencia política en la Argentina actual. Espacios Políticos, 30-33.

Couloumbis, T., \& Wolfe, J. (1986). Introduction to International Relations: power and justice.

D'Alessandro, M. (2013). Las desventajas de la Política Comparada en América Latina: énfasis en el caso Argentino. Debates, V.7, N.3, 89-110.

Duque Daza, J. (2014a). La ciencia política en Colombia. La construcción de una comunidad académica. Cali: Universidad del Valle.

Duque Daza, J. (2014b). La investigación formativa en ciencias sociales. Acerca de los trabajos de grado, Documento de trabajo, Instituto de Educación y pedagogía, Cali: Universidad del Valle.

Duque Daza, J. (2014). La Ciencia Política en Colombia. Análisis de los planes de estudio, sus áreas y sus énfasis. Papel Político, Vol. 19 No. 2, 377-411.

Graziano, L. (1986). Para una historia de la Ciencia Política. introducción a La Ciencia Política en Italia. Obtenido de https://ddd.uab.cat/pub/papers/02102862n28/02102862n28p27.pdf p.29

Guy Peters, B. (2003). El Nuevo Institucionalismo. En La teoría institucional en ciencia política. Barcelona, España: Gedisa S.A.

Guy, P. (2001). Las instituciones políticas: lo viejo y lo nuevo. En G. y. (eds.), Nuevo Manual de Ciencia Política. Istmo. 
Hall, P. A., \& Taylor, R. C. (1996). Political Science and the Three New Institutionalisms. Obtenido de paper presented by Professor Hall a member of the MPIFG Scientific Advisory Board, as a public lecture during the Board's meeting on May 9, 1996: http:// www.mpifg.de/pu/mpifg_dp/dp96-6.pdf

Hartlyn, J. (2010). La Ciencia Política y el estudio de la política comparada en los Estados Unidos: tendencias y diálogos con la Ciencia Política en América Latina. Anuario Americanista Europeo, n. 8, 144-156.

Hedström, P., \& Udehn, L. (2009). Analytical Sociology and Theories of the Middle-range. En P. Hedström, \& P. Bearman, he Oxford Handbook of Analytical Sociology (en inglés). Oxford: Oxford Universiy.

Instituto Tecnológico Autónomo de México (s.f). LICENCIATURA EN CIENCIA POLÍTICA. Ciudad de México, México. Recuperado de: https://politica.itam.mx/sites/default/ files/programas/planes/plan-de-estudios-de-la-licenciatura-en-ciencia-politica-del-ITAM.pdf

James, A. E., \& Alesina, A. (2001). Economía política. Una visión general. En R. G. Ed, Manual de Ciencia Política (págs. 937-980).

King, G., Keohane, R., \& Verba, S. (2000). El diseño de la investigación social. Madrid: Alianza Editoria.

Laitin, D. (2004). The Political Science Discipline. En The Evolution of Political Knowledge: democracy, autonomy and Conflict in comparative and international politics. Ohio State: University Press.

Leiras, M., Abal Medina, J., \& D'Alessandro, M. (2005). "La ciencia política en Argentina: el camino de la institucionalización dentro y fuera de las aulas universitarias". Ciencia Política, (25)1, 76-91.

Mair, P. (2001). Política comparada: una visión general. En R. G. Ed, Manual de Ciencia Política (págs. 447-484). Istmo.

March, J., \& Olsen, J. (1984). The New Institutionalism: Organizational Factors in Political Life. American Political Science Review No 78.

March, J., \& Olsen, J. (1989). Rediscovering Institutions. The Organizations Basis of Polititics. Nueva York: Free Press.

Meynaud, J. (1960 [1958]). Introducción a la ciencia política. Madrid: Taurus.

Munck, G., \& Snyder, R. (2007). Who publishes in comparative politics? Studying the world from the United States. PS: Political Science \& Politics. PS: Political Science \& Politics, 339-346.

Negretto, G. L. (2004). Nota del editor. El rumbo de la ciencia política. Política y gobierno. CIDE V. XI, N. 2, 347-348.

Nelson J. B. (1996). Políticas públicas y administración: Una visión general. En Robert Gooding y Hans Dieter Klingemann. (Eds.), Nuevo manual de Ciencia política (pp. 795860). Madrid: Istmo.

Nohlen, D. (2006). Ciencia política en América Latina. En Diccionario de ciencia política. México: Porrúa.

Nohlen, D. (2012 [2002]). ¿Cómo estudiar ciencia política? Una introducción de trece lecciones. Madrid: Marcial Pons, Ediciones Jurídicas y Sociales.

North, D. (1993). Instituciones, cambio institucional y desempeño económico. México: Fondo de Cultura Económica.

Pierson, P., \& Skopol, T. (2008). El institucionalismo histórico en ciencia política. uruguaya de Ciencia Política 17(7).

Ramos Hilario, J. (2016). Ciencia política en el Perú: avances y retrocesos. Obtenido de revista Politikon: https://www.revistapolitikon.com.ar/ciencia-politica-en-el-peru-avances-y-retrocesos/

Restrepo, B. (2003). Investigación formativa e investigación productiva de conocimiento en la universidad. Nómadas No 18. 
Ricci, D. (1987). Politics, Scholarship, and Democracy. En The Tragedy of Political Scienci. Yale University Press.

Sarquis, David. (2011). ¿Para qué sirve el estudio teórico de las relaciones internacionales? Revista de Relaciones Internacionales de la UNAM. 111, 39-62.

Seidelman, R., \& Harpham, E. J. (1985). Disenchanted realists: Political science and the American crisis, 1884-1984. New Haven: Albany: Suny Press; Yale University Press.

Universidad Central del Paraguay (s.f). Información carrera de Ciencia Política. Asunción, Paraguay. Recuperado de: http://www.central.edu.py/carrera/ciencias-politicas-10

Universidad Nacional de Asunción (2007). Escuela de Ciencias Sociales y Ciencias Políticas, Planes de estudios. Asunción, Paraguay. Recuperado de: http://www.der.una. py/index.php/academico/ciencias-sociales/planes-de-estudios

Universidad Nacional del Este (2004). Ciencia política. Paraguay. Recuperado de: http:// www.une.edu.py/web/images/pdf/CienciasPoliticasPlandeEstudios.pdf

Universidad Autónoma de Santo Domingo (2018) ESCUELA DE CIENCIAS POLÍTICAS, República Dominicana. Recuperado de: https://www.uasd.edu.do/index.php/escuelas/ciencias-politicas

Universidad Nacional Autónoma de Honduras (2018). ASIGNATURA GENERAL DE CIENCIAS POLITICAS Y DERECHOS HUMANOS. Tegucigalpa, Honduras. Recuperado de: https://cienciassociales.unah.edu.hn/carreras/asignatura-general-de-ciencias-politicas-y-derechos-humanos/

Universidad de Panamá (2018). Licenciatura en Ciencia Política. Provincia de Panamá. Recuperado de: https://universidades.pa/universidades/universidad-de-panama-up/licenciatura/ciencia-politica/plan-estudios

Universidad Nacional Federico Villareal (2018) Escuela Profesional de Ciencia Política. Lima, Perú. Recuperado de: http://www.unfv.edu.pe/facultades/fdcp/escuela-profesional-de-ciencia-politica

Universidad Mayor Nacional de San Marcos (2018). Escuela Académica de Ciencia Política. Lima, Perú. Recuperado de: https://derecho2.unmsm.edu.pe/eapcp.html

Pontificia Universidad Católica del Perú (2018). Ciencia Política y Gobierno. Lima, Perú. Recuperado de: https://www.pucp.edu.pe/carrera/ciencia-politica-y-gobierno/

Universidad Antonio Ruiz Montoya (2018). CIENCIA POLÍTICA. Lima, Perú. Recuperado de: https://www.uarm.edu.pe/Facultades/ciencia-politica

Universidad Nacional Autónoma de México (2016). Licenciatura en Ciencias Políticas y Administración Pública. Ciudad de México, México. Recuperado de: http://www. politicas.unam.mx/cep/?page_id=1723

Universidad Católica de Chile (s.f). Ciencia Política. Santiago, Chile. Recuperado de: http:// admisionyregistros.uc.cl/images/pdf/folletos_carreras/c_politica.pdf

Universidad de la República (s.f). Licenciatura en Ciencia Política. Montevideo, Uruguay. Recuperado de: http://www.universidad.edu.uy/carreras/majorMorelnfo/majorId/137

Wæver, O. (s.f). Still a Discipline After All These Debates? En J. J. (eds.), Scientific Realism and International Relations. Nueva York: Palgrave Macmillan.

Whitaker, R. (2013). Political Science. Obtenido de The Canadian Encyclopedia: https:// www.thecanadianencyclopedia.ca/en/article/political-science

Zolo, D. (2006). La tragedia de la ciencia política. Metapolítica No 49.

Notas.

i Este artículo hace parte del trabajo de investigación Politólogos y politología. Campos de conocimiento y oficio de politólogo desarrollado en la Universidad del valle Colombia, 2016-208 